\title{
ENFOQUES, EXPERIENCIAS Y PROPUESTAS PARA LA MEJORA DE LA COMPETITIVIDAD TERRITORIAL DE LAS ÁREAS VITIVINÍCOLAS: LAS DENOMINACIONES DE ORIGEN PROTEGIDAS DE LA PROVINCIA DE ZARAGOZA ${ }^{1}$
}

\author{
Ana Isabel Escalona Orcao \\ Blanca Loscertales Palomar \\ Eugenio Climent López \\ GEDETUZ: Grupo de Estudios de Desarrollo Territorial de la Universidad de Zaragoza \\ Instituto de la Investigación en Ciencias Ambientales (IUCA) \\ aescalon@unizar.es, bloscer@unizar.es, ecliment@unizar.es
}

\section{RESUMEN}

Se exploran las estrategias que pueden adoptar los agentes de los espacios afectados por la mundialización del mercado del vino, teniendo en cuenta diversos enfoques y modelos productivos y territoriales. Una encuesta a las bodegas de las Denominaciones de Origen Protegidas de la provincia de Zaragoza (España) muestra iniciativas de innovación en tecnología, marketing, imagen, gestión, recursos humanos, búsqueda de reconocimiento y exportación. Se confirma la interdependencia positiva entre el territorio y las producciones locales y se realizan propuestas para que el sector vitivinícola siga desempeñando un importante papel en el desarrollo territorial.

Fecha de recepción: noviembre 2011.

Fecha de aceptación: enero 2013.

1 El artículo presenta resultados obtenidos en el marco de los siguientes proyectos de investigación: Nuevos retos para el desarrollo territorial. Los espacios del vino y del calzado en la provincia de Zaragoza y Gobernanza, innovación y convenciones en las comarcas vitivinícolas de Aragón: tipología y prospectiva de Denominaciones de Origen a partir de la teoría de los «mundos de producción». El primero resultó seleccionado en la I Convocatoria de premios Investigación Cuarto Espacio de la Diputación Provincial de Zaragoza y ha sido llevado a cabo por el equipo de investigadores integrado por los autores. El segundo forma parte de un proyecto coordinado subvencionado por el Ministerio de Ciencia e Innovación, (CSO2008-05793-C03-02/GEOG) cuya investigadora principal es Luisa María Frutos Mejías. Los autores agradecen a los patrocinadores de ambos proyectos el apoyo recibido. 
Palabras clave: Mundialización vitivinícola, desarrollo rural, Denominación de Origen Protegida, Zaragoza.

\begin{abstract}
Strategies implemented in the rural areas affected by the globalization of the wine market are explored; various approaches and models of production and territorial development are taken into account. The survey of wineries in three wine areas of Zaragoza (Spain) shows that firms innovate in fields such as technology, marketing, management, human resources, recognition and exports. The analysis confirms the positive interdependence between the territory and local products; proposals aimed to achieve that the wine sector continues playing an important role in rural development are made.
\end{abstract}

Key words: Globalization of wine, rural development, Protected Designations of Origin, Zaragoza.

\title{
I. INTRODUCCIÓN
}

La problemática actual de las áreas especializadas en la producción de vino deriva, en buena parte, de la dinámica de la vitivinicultura en el marco de la mundialización productiva. Entre los principales procesos y retos a los que deben hacer frente, destacan la incierta situación actual de los mercados internacionales, los cambios en las preferencias de los consumidores, los ajustes en las estructuras empresariales o la necesidad de adoptar nuevas estrategias productivas y competitivas por parte de los agentes sociales y económicos. En los espacios vitivinícolas tradicionales españoles, como los que estudiamos en este artículo, la competencia causada por la entrada en el mercado global de nuevos países exportadores, el descenso del consumo del vino o la proliferación de denominaciones de origen protegidas (DOP) en el ámbito nacional, han debilitado su potencial competitivo y amenazan su futuro (Observatorio, 2010). Por ello, sus agentes económicos y sociales vienen esforzándose por poner en marcha y potenciar iniciativas empresariales y territoriales que les permitan sacar partido de sus fortalezas y de las nuevas oportunidades que este complejo contexto les brinda. Esta problemática es semejante a la de otras áreas rurales afectadas por la mundialización productiva en sectores clave de sus economías, que dejan de serlo y suscitan la necesidad de que se desarrollen o promuevan actividades alternativas.

Con este artículo pretendemos hacer una aportación al debate sobre qué estrategias se deben adoptar en territorios cuya base económica tradicional se ve afectada por una reestructuración global. Para ello exponemos, en primer lugar, dos marcos teóricos apropiados para interpretar las estrategias empresariales y territoriales suscitadas por los procesos de mundialización productiva: la teoría de las convenciones y la del nuevo paradigma rural. Seguidamente analizamos la situación de la vitivinicultura en las tres denominaciones de origen protegidas de la provincia de Zaragoza (Comunidad Autónoma de Aragón, España)².

2 La provincia de Zaragoza es el ámbito territorial de la institución patrocinadora de la investigación realizada (nota 1). 
La vinculación histórica a la vitivinicultura convierte a esta actividad en la principal impulsora, o una de las principales, de la dinamización socioeconómica local. Ha servido además para la conservación de un importante paisaje cultural que ahora puede ser revalorizado y está en la base del enoturismo. Entendemos que la opinión de los productores sobre todas estas cuestiones, a pesar de ser muy relevante, no siempre es recogida y por ello aportamos los resultados de una encuesta en las bodegas sobre su actividad y sobre su percepción del potencial de la vitivinicultura para seguir sustentando el desarrollo local. La encuesta ha sido concebida teniendo en cuenta los factores que conforman los actuales modelos competitivos en el ámbito vitivinícola y las estrategias empresariales que, según la teoría de las convenciones, serían esperables en el actual proceso de reestructuración productiva. Igualmente hemos asumido los principios del nuevo paradigma rural (OCDE, 2006), según el cual las llamadas especificidades locales, ya sean de carácter patrimonial, medioambiental o productivo, generan ventajas competitivas para los territorios, lo que vendría a justificar que la vitivinicultura siga siendo considerada como instrumento de primer orden para el desarrollo de los municipios de las denominaciones estudiadas (OCDE, 2006).

La explotación de los resultados de la encuesta deja patente que en las DOP zaragozanas se han puesto en marcha iniciativas de interés en relación con la innovación tecnológica, el marketing y la imagen de los productos, la gestión y administración y la formación de recursos humanos, entre otros aspectos. La percepción generalizada de que los consumidores apuestan por un vino de calidad está en la base de las mejoras observadas y, del mismo modo, ha estimulado la búsqueda del reconocimiento de los vinos propios en diferentes certámenes y publicaciones de gran prestigio, tanto nacional como internacional, y la creciente apertura al mercado exterior. El análisis realizado también viene a confirmar uno de los supuestos del nuevo paradigma rural: la interdependencia positiva que se establece entre el territorio y los productos locales. De hecho, aunque la figura jurídica de la Denominación de Origen Protegida es criticada en algunos casos, los empresarios consultados no cuestionan que la imagen de los vinos se promocione asociada al territorio, porque son conscientes de la contribución de los vinos a su desarrollo y, además, valoran la influencia positiva del territorio y de su historia de cara a la promoción de los vinos.

El artículo concluye reafirmando el potencial de la vitivinicultura para seguir desempeñando un importante papel en el desarrollo de las denominaciones de origen protegidas estudiadas, siempre que todas las instancias implicadas, públicas y privadas, asuman los retos que les son propios.

\section{LA COMPETITIVIDAD Y EL DESARROLLO DE LAS ÁREAS VITIVINÍCOLAS. MODELOS PRO- DUCTIVOS Y TERRITORIALES}

\section{Un contexto productivo y territorial complejo}

Los datos globales de las DOP españolas indican que el número de bodegas embotelladoras, que en 2005 era de 2.892, se incrementó en los últimos años hasta las 3.271 de 2011, mientras que la superficie de viñedo pasó de 621,7 a 591,7 miles de hectáreas; el número de viticultores se ha reducido también en las mismas fechas, pasando de 159.925 a 138.052 (Ministerio de Agricultura, Alimentación y Medio Ambiente, 2012). Los desafíos que afec- 
tan a las zonas con tradición vitivinícola, derivan de que los vinos han venido siendo una especialidad productiva de estas tierras, a las que han aportado ventajas competitivas. Sin embargo, esta situación se ha visto afectada por la incorporación con fuerza al mercado internacional de nuevos países productores. Estos países emergentes se sitúan en áreas climáticas similares a las de la Europa mediterránea (en Australia y Nueva Zelanda, Norteamérica y Sudamérica, Sudáfrica), disponen de una legislación menos rígida, han realizado una gran inversión en tecnología y desarrollan prácticas productivas distintas, que les llevan a competir con éxito en la exportación de vinos situados en el segmento de precios medios y medios altos (tabla 1).

Tabla 1

MODELOS BÁSICOS DE PRODUCCIÓN EN LAS ÁREAS VITIVINÍCOLAS

\begin{tabular}{|c|c|c|}
\hline Criterio descriptivo (selección) & $\begin{array}{l}\text { Modelo productivo en los países } \\
\text { tradicionales }\end{array}$ & $\begin{array}{l}\text { Modelo productivo en los países } \\
\text { nuevos productores }\end{array}$ \\
\hline $\begin{array}{l}\text { Procedencia de la materia } \\
\text { prima }\end{array}$ & El propio territorio & $\begin{array}{l}\text { Zonas diferentes del propio } \\
\text { territorio }\end{array}$ \\
\hline Tipo de actividad & Tradicional agroindustrial & Industrial comercial \\
\hline Carácter de la producción & $\begin{array}{l}\text { Heterogénea y ajustada a las } \\
\text { prácticas culturales permiti- } \\
\text { das }\end{array}$ & $\begin{array}{l}\text { Grandes volúmenes con } \\
\text { calidad alta y homogénea, } \\
\text { menos reglamentada y vin- } \\
\text { culada al territorio }\end{array}$ \\
\hline Elemento de diferenciación & $\begin{array}{l}\text { El lugar de origen avalado } \\
\text { por una figura como la DOP } \\
\text { o semejante }\end{array}$ & $\begin{array}{l}\text { La marca y la variedad de } \\
\text { la uva }\end{array}$ \\
\hline $\begin{array}{l}\text { Clave para la competitivi- } \\
\text { dad }\end{array}$ & $\begin{array}{l}\text { Mejorar la calidad y singu- } \\
\text { larizar el producto }\end{array}$ & Calidad alta y homogénea \\
\hline Estrategia competitiva & $\begin{array}{l}\text { Una imagen que incorpore } \\
\text { valores complementarios } \\
\text { (historia, cultura, tradición, } \\
\text { territorio, paisaje) y los pro- } \\
\text { yecte al exterior }\end{array}$ & $\begin{array}{l}\text { Aumento de la oferta y estí- } \\
\text { mulo del consumo mediante } \\
\text { técnicas de mercado }\end{array}$ \\
\hline Estructura empresarial & $\begin{array}{l}\text { Concentración empresarial } \\
\text { media-baja }\end{array}$ & $\begin{array}{l}\text { Grandes empresas fuertes y } \\
\text { alta concentración }\end{array}$ \\
\hline Orientación exportadora & Variable & Alta \\
\hline Garantía ante el consumidor & $\begin{array}{l}\text { Mediante el origen o la mar- } \\
\text { ca colectiva (DOP) }\end{array}$ & $\begin{array}{l}\text { Mediante la marca o la em- } \\
\text { presa }\end{array}$ \\
\hline
\end{tabular}

Fuentes: Barco et al. (2005 y 2007) y Escalona et al. (2009). Elaboración propia.

El dinamismo competitivo de los países emergentes les ha llevado a aportar el $30 \%$ de la producción mundial mientras que la cuota de los países tradicionalmente productores es ya sólo del $65 \%$. El retroceso en la cuota de mercado coincide con el descenso del consumo 
del vino, producto de demanda elástica, debido a la crisis económica, de modo que la exportación se ha convertido en una salida imprescindible para la producción. En este complejo contexto se enmarcan los debates suscitados en su día a propósito de la aprobación de la nueva Organización Común del Mercado (OCM) del sector vitivinícola, justificada por los diversos problemas que le venían afectando, como la ya citada disminución del consumo, el aumento de los excedentes o el deterioro de la renta de los productores agrarios. Si bien las anteriores OCM introdujeron diversas medidas para adecuar la producción a la demanda de los mercados internacionales -como la renovación varietal y las mejoras en la mecanización- las disposiciones adoptadas por la Unión Europea en la OCM de 2008 han sido criticadas por partir de un único modelo europeo de producción y primar medidas como el arranque de viñedos en vez de favorecer el consumo, incentivar la mejora de la calidad, promover la comunicación en el mercado interior de la Unión Europea o proporcionar ayudas para actuar en el exterior, entre otras posibles (Barco, 2007).

En muchos aspectos, la problemática de las áreas vitivinícolas tradicionales no es muy distinta de la que afecta a áreas rurales especializadas en otros sectores que se han visto afectados por la mundialización productiva, como el textil o el calzado (Scott, 2006; Sánchez y Arévalo, 2007; Climent, Escalona y Loscertales, 2011). Con frecuencia, sus empresas no pueden adaptarse al nuevo contexto competitivo y se ven abocadas a introducir ajustes productivos o incluso a su cierre. De esta forma los sectores económicos afectados pierden su condición estratégica para el desarrollo de los territorios y éstos deben desarrollar otras competencias o promover actividades alternativas (Schamp, 2005; Scott, 2006).

\section{Las estrategias productivas: la búsqueda de la calidad y la creación de valor}

Los complejos retos a los que se enfrentan las empresas de las áreas vitivinícolas exigen respuestas adecuadas para mejorar o no perder su competitividad en el actual escenario de reestructuración productiva mundial. Entre las posibles teorías explicativas de las estrategias adoptadas, destaca la teoría de las convenciones, desarrollada a partir del concepto acuñado en su día por Salais y Storper (1992). Los fundamentos de dicha teoría son, por una parte, la consideración de la economía como un proceso colectivo de producción y consumo y, por otra, la relación entre el comportamiento de los diferentes agentes y una percepción parecida o coincidente del contexto económico (Storper, 1997). Estos planteamientos se han venido aplicando al análisis de las actuaciones empresariales en diversos sectores y contextos, singularmente en la industria agroalimentaria (Murdoch y Miele, 1999; Amilien, Fort y Ferras, 2007; Ponte, 2009). A modo de ejemplo pueden citarse investigaciones recientes realizadas en España en las que se emplea dicha teoría para estudiar los procesos de innovación en las áreas vitivinícolas (Lindkvist y Sánchez, 2008; Sánchez, Aparicio y Alonso, 2010; Frutos et al., 2011).

La teoría de las convenciones permite relacionar las estrategias productivas con la percepción que tienen los empresarios de la actual reestructuración mundial vinícola. Este enfoque ha sido aplicado en un análisis comparado de las adaptaciones productivas recientes en dos áreas especializadas, respectivamente, en los sectores del calzado y del vino (Escalona, Loscertales y Climent, 2011). La tabla 2 presenta una relación de prácticas empresariales admitidas tácitamente que responderían a la reestructuración productiva en curso. Como 
Tabla 2

EJEMPLOS DE PRÁCTICAS EMPRESARIALES EN EL MARCO DE LA REESTRUCTURACIÓN DE LAS ACTIVIDADES VITIVINÍCOLAS

\begin{tabular}{|c|c|c|}
\hline \multirow{2}{*}{$\begin{array}{l}\text { CONVENCIÓN/ } \\
\text { ÁMBITO DE } \\
\text { REFERENCIA }\end{array}$} & \multicolumn{2}{|c|}{$\begin{array}{l}\text { PRÁCTICAS POSIBLES EN UN CONTEXTO DE REESTRUCTURACIÓN } \\
\text { PRODUCTIVA }\end{array}$} \\
\hline & $\begin{array}{l}\text { PERCEPCIÓN QUE LAS } \\
\text { JUSTIFICA }\end{array}$ & EJEMPLOS \\
\hline COMERCIAL & $\begin{array}{l}\text { Situación del mercado } \\
\text { nacional e internacional }\end{array}$ & $\begin{array}{l}\text { - Orientación hacia determinados nichos } \\
\text { de mercado } \\
\text { - Búsqueda de mercados atractivos } \\
\text { - Selección de los canales de venta }\end{array}$ \\
\hline INDUSTRIAL & $\begin{array}{l}\text { Preferencias del consu- } \\
\text { midor por determinados } \\
\text { productos y procesos de } \\
\text { producción }\end{array}$ & $\begin{array}{l}\text { - Elección de la materia prima adecuada } \\
\text { - Utilización de tecnologías productivas } \\
\text { específicas } \\
\text { - Diversificación productiva } \\
\text { - Reducción de la gama productiva }\end{array}$ \\
\hline $\begin{array}{l}\text { DOMÉSTICOO } \\
\text { PROPIO DEL } \\
\text { ENTORNO }\end{array}$ & $\begin{array}{l}\text { Aprecio del consumidor } \\
\text { por los valores tradicio- } \\
\text { nales y patrimoniales } \\
\text { del territorio }\end{array}$ & $\begin{array}{l}\text { - Utilización preferentemente de materias } \\
\text { - } \text { primas de la zona, haciéndolo constar } \\
\text { cional } \\
\text { - Trazabilidad } \\
\text { - Promoción del territorio en productos e } \\
\text { instalaciones } \\
\text { - Conservación del paisaje tradicional } \\
\text { - Enoturismo }\end{array}$ \\
\hline ECOLÓGICO & $\begin{array}{l}\text { Valoración por el con- } \\
\text { sumidor de los produc- } \\
\text { tos obtenidos de forma } \\
\text { sostenible }\end{array}$ & $\begin{array}{l}\text { - Velar por la sostenibilidad del proceso } \\
\text { productivo } \\
\text { - Obtención de acreditaciones oficiales } \\
\text { - Establecimiento de líneas de productos } \\
\text { ecológicos }\end{array}$ \\
\hline PÚBLICO & $\begin{array}{l}\text { Importancia del recono- } \\
\text { cimiento o la difusión } \\
\text { de la marca propia }\end{array}$ & $\begin{array}{l}\text { - Presencia en medios especializados } \\
\text { - Participación en certámenes de prestigio }\end{array}$ \\
\hline CÍVICO & $\begin{array}{l}\text { Valoración de la contri- } \\
\text { bución de las empresas } \\
\text { al bienestar social }\end{array}$ & $\begin{array}{l}\text { - Elaboración de productos saludables } \\
\text { - Participación en campañas de apoyo a } \\
\text { causas humanitarias }\end{array}$ \\
\hline
\end{tabular}

Fuentes: Escalona et al, 2011 y Frutos et al, 2011. Elaboración propia.

establece la teoría, las prácticas contempladas se refieren a aspectos importantes para la calidad y competitividad de los productos y resultan coherentes con las expectativas que tienen los empresarios respecto de las actuales preferencias de los consumidores y de los mercados. 
Las investigaciones realizadas en otros espacios afectados por la restructuración vitivinícola (Aparicio et al, 2008; Escalona, Loscertales y Climent, 2011; Castelló et al, 2010) han dejado patente que sus empresarios tomaban iniciativas semejantes a las propuestas en la tabla. Ello permite adoptar como hipótesis, también para este trabajo, que entre los actuales factores de competitividad aplicados en las empresas sigue vigente el «saber hacer» propio de una ancestral tradición en el cultivo de la vid y la elaboración de vino. Cabe esperar también que se conceda importancia a la innovación, la mejora de las marcas, imagen y diseño, al control de la distribución o a la conservación del entorno. No obstante los factores que se han revelado fundamentales y más selectivos se relacionan con las expectativas de un consumidor más educado y exigente, que se interesa por la calidad del producto y por aquellos aspectos que lo singularizan. Ello justificaría la mejora de su presentación, de la información que se aporta en la botella sobre el vino (características, certificación de su origen, de su calidad y de la sostenibilidad de la producción) o de la imagen del mismo en función de los posibles reconocimientos obtenidos en medios y certámenes especializados (Barco, 2007; Barco, Langreo y Navarro, 2005; Albisu, 2004; Lindkvist y Sánchez, 2008).

La viabilidad de iniciativas empresariales como las propuestas puede chocar con el hecho de que en la mayor parte de las DOP vinícolas españolas, incluidas las estudiadas en este trabajo, predominan las cooperativas y las pequeñas empresas, bajo la forma de sociedades de capital. La escasa dimensión dificulta la adopción de los modelos estratégicos de éxito y explica, además, la proliferación de marcas que existen en el mercado, hecho considerado negativo y que se ve complicado por la tendencia de muchas bodegas a tener demasiadas marcas. Hay que señalar, en todo caso, que para la competitividad de las empresas un factor económico más importante que la dimensión empresarial es la creación de valor, de modo que bodegas pequeñas y medianas, con una alta creación de valor, están mejor preparadas y son más eficaces que una bodega grande para que sus productos sean más apreciados en el mercado (Albisu, 2004). De hecho en los municipios vitivinícolas españoles existen pequeñas bodegas que incorporan en sus instalaciones otras actividades diferentes de la producción y crianza de vinos, como el enoturismo o la venta de vinos en la bodega. Destacan por la calidad de sus vinos y por el prestigio alcanzado en el ámbito nacional e internacional. Estas prácticas vendrían a confirmar el peso en las decisiones productivas de los criterios domésticos o expresivos de la vinculación con el entorno.

\section{Las estrategias territoriales. El nuevo paradigma rural}

El impacto de la reestructuración productiva en el sector vitivinícola se ha dejado sentir en las áreas productoras tradicionales. Por ello es oportuno el debate internacional abierto hace algunos años sobre qué estrategias y políticas deben implantarse en estos territorios para conseguir mantener o reforzar su desarrollo en el actual contexto competitivo. Entre los modelos propuestos destaca el nuevo paradigma rural, que propugna políticas centradas en el aprovechamiento de las nuevas oportunidades que la mundialización económica u otros factores brindan a las áreas rurales (OCDE, 2006). Según dicho paradigma, la competitividad territorial -que sigue siendo el objetivo de las políticas de desarrollo- se alcanzaría mediante el aprovechamiento, entre otros factores, de las especificidades patrimoniales, medioambientales o productivas de los territorios. Destaca igualmente el paso desde un enfoque sectorial, 
centrado en subsidiar actividades en declive, a otro plurisectorial consistente en invertir en las diferentes actividades que se consideren estratégicas para los territorios (Escalona et al, 2011). Este enfoque viene a reforzar las consideraciones expuestas en su día por diversos autores en relación con los beneficios específicos aportados por las actividades vitivinícolas en sus respectivos territorios (tabla 3).

Tabla 3

EJEMPLOS DE BENEFICIOS TERRITORIALES GENERADOS POR LAS ACTIVIDADES VITIVINÍCOLAS

1. Mantenimiento de un elevado número de explotaciones vitícolas que constituyen una importante fuente de ingresos en muchos municipios.

2. Distribución por el territorio rural de un elevado número de empresas medianas y pequeñas que le proporcionan un importante tejido industrial.

3. Impulso a la implantación y desarrollo de una amplia gama de actividades vinculadas, como proveedores de materias primas, de componentes y de servicios.

4. Creación y mantenimiento de un paisaje vitícola de alto valor ambiental, que resulta cada vez más apreciado como destino del enoturismo.

5. Promoción del territorio a través de su producción de vino.

6. Contribución a la identidad de un territorio.

Fuente: Escalona, Loscertales y Climent (2009) a partir de Barco et al. (2007) y Maby (2000). Elaboración propia.

Los efectos positivos consignados en la tabla 3 demuestran que la presencia de empresas vitivinícolas en el territorio es siempre ventajosa a pesar de su pequeña dimensión. En primer lugar, la existencia de empresas vinícolas está asociada a la de explotaciones de viñedo, cuyo mantenimiento favorece, brindando así a muchos municipios su principal o una de sus principales fuentes de ingresos. En las DOP españolas y europeas, encontramos bodegas que disponen de explotación agraria propia y están situadas en medio de ella. Es frecuente que dicha explotación incorpore tierras muy diversas para facilitar la adaptación de las variedades de especies viníferas utilizadas para la producción de vino. Por otra parte, la alta densidad relativa de unidades productivas sostiene el tejido industrial rural favoreciendo igualmente el desarrollo de actividades auxiliares o complementarias de diversa naturaleza. Las oportunidades de trabajo que proporcionan se reparten por todos los municipios como alternativa a otras actividades tradicionales y constituyen un factor de atracción de trabajadores y de dinamización social y económica.

La conservación y valorización del medio ambiente constituyen otro ejemplo de impacto positivo del sector vitivinícola, generándose un paisaje vitícola de alta calidad y muy apreciado en el marco de las diversas actividades vinculadas al enoturismo (Barco et al., 2007; Sommers, 2008). Son cada vez más las bodegas que se introducen en este negocio, que conoce una alta demanda por parte de turistas de alto poder adquisitivo interesados en el mundo del vino. Veremos que así sucede ya en las denominaciones estudiadas, algunas de cuyas bodegas diversifican sus actividades incorporando también instalaciones hoteleras de calidad. 
Por todo lo expuesto, existen razones suficientes para que las actividades vitivinícolas sigan siendo estratégicas en el marco de los nuevos modelos de desarrollo rural. El mantenimiento de las actividades empresariales es un buen síntoma del potencial de la vinicultura para ello, especialmente de aquellas empresas que con sus estrategias hacen más competitivos a los territorios. En todo caso, los empresarios desempeñan un papel clave y, por ello, su percepción y experiencia es muy valiosa para fundamentar y elaborar políticas oportunas. Con este fin aportamos más adelante los resultados de la encuesta llevada a cabo a los empresarios de las DOP de la provincia de Zaragoza.

\section{LAS ZONAS VITIVINÍCOLAS CON DENOMINACIÓN DE ORIGEN PROTEGIDA DE LA PRO- VINCIA DE ZARAGOZA. ASPECTOS DE SU TRAYECTORIA RECIENTE}

La provincia de Zaragoza cuenta con tres DOP vitivinícolas. La de Cariñena, reconocida en 1932, es una de las más antiguas de España; aglutina a 14 municipios y es la más extensa de Aragón. El territorio de la DOP Campo de Borja, que data de 1980, está formado por 16 municipios. Por su parte el espacio de la DOP Calatayud, establecida en 1989, está integrado por 46 municipios (figura 1). La historia de los tres espacios muestra cómo el desarrollo económico y territorial aparece fuertemente vinculado al de la vitivinicultura. Destaca el carácter pionero de muchas de las iniciativas aquí adoptadas, como la ya citada implantación de la figura de la DOP o el desarrollo del cooperativismo, ya que la mayor parte de las cooperativas vinícolas de estas áreas se crean entre 1945 y 1965. Las cooperativas mantienen su importancia en la actualidad, pues producen más del 95\% del vino de las tres DOP.

La mayor parte de los municipios que integran las áreas estudiadas, tienen poca población: sólo 12 superan los 1.000 habitantes. Su dimensión económica también es pequeña, lo que realza la importancia de las actividades vitivinícolas en el desarrollo local. En la de Cariñena las 16.000 hectáreas de viñedo representaban casi una quinta parte de su extensión total y el $31 \%$ de las tierras cultivadas en el año 2007. Ese año se ocupaban de su mantenimiento unos 2.000 viticultores, a los que habría que añadir quienes trabajan en la actividad vinícola, que da empleo a casi el $44 \%$ de los afiliados a la Seguridad Social por el sector industrial y al 23\% de todos los empleados del espacio estudiado (Loscertales, 2009; Loscertales et al., 2011). En la DOP Campo de Borja, existían 7.414 hectáreas de viñedo, que suponían una octava parte aproximadamente de toda el área. Estas actividades proporcionaban el $24 \%$ de los empleos y representaban el $48 \%$ de sus empresas industriales. En la DOP Calatayud, por último, sus 5.621 hectáreas de viñedo se repartían por una extensión 3 y 2,3 veces mayor que las de las DOP de Borja y Cariñena, respectivamente. Aunque ello indica que la densidad del viñedo es menor, la vitivinicultura representa una base económica importante para muchos pequeños municipios, con un elevado peso en la agricultura e industria locales. De hecho la industria en este territorio está claramente dominada por el sector de productos alimenticios y bebidas, que supone el $48 \%$ del empleo y el $85 \%$ de las empresas.

La de Cariñena ocupa la $11^{a}$ posición entre las DOP españolas, atendiendo a la superficie cultivada, lo cual le da una cierta relevancia a escala nacional, si bien queda bastante lejos de La Mancha o Rioja, que son las dos primeras. Campo de Borja y Calatayud se encuentran entre las medianas, con extensiones comparables a Rías Baixas o Toro (Ministerio de Agricultura, Alimentación y Medio Ambiente, 2012). 
En las DOP de Campo de Borja y Calatayud el número de bodegas ha experimentado un crecimiento muy ligero entre 2001 y 2011: de 15 a 17 y de 14 a 16, respectivamente. La de Cariñena siguió la misma tendencia hasta 2009, pasando de 50 a 55, pero en las dos últimas campañas, el Consejo Regulador ha implantado nuevos sistemas de control de calidad y auditoría, que algunas bodegas no han podido incorporar, por lo que han sido dadas de baja; actualmente quedan 35 (Ministerio de Agricultura, Alimentación y Medio Ambiente, 2012). Son datos que indican que el dinamismo empresarial en las DOP zaragozanas está por debajo del observado en la cuarta DOP aragonesa, la del Somontano de Barbastro (Castelló et al, 2010).

LAS DENOMINACIONES DE ORIGEN PROTEGIDAS VINICCOLAS DE LA PROVINCIA DE ZARAGOZA
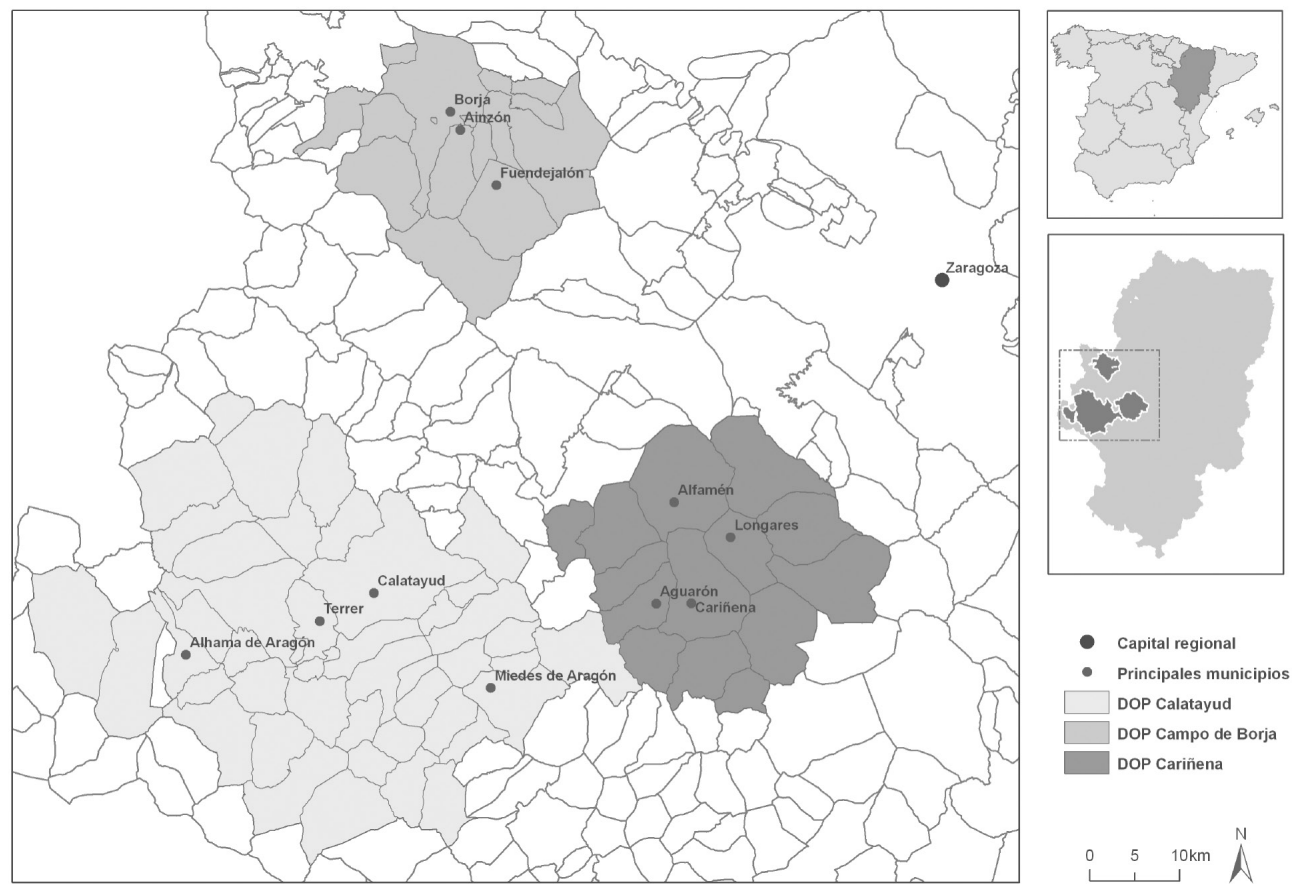

- Capital regional

- Principales municipios DOP Calatayud DOP Campo de Borja DOP Cariñena

Las actividades vitivinícolas conocen en los territorios estudiados una continua transformación, si bien no es homogénea ni por DOP ni en el seno de cada una de las mismas. La innovación afecta tanto al sector de la viticultura como a la posterior producción de vino en la bodega o sector agroindustrial. La incorporación de nuevos modos de cultivo, especialmente el cultivo en espaldera y el regadío, de nuevas variedades de uva y de diversas mejoras en la vendimia, son aspectos que cabe destacar y a los que se unen las innovaciones en el proceso productivo (equipo, barricas, personal cualificado, entre otros aspectos).

La figura 2 muestra el peso de las nuevas variedades introducidas para adaptarse a unos consumidores que no sólo son cada vez más exigentes, sino que han cambiado sus gustos y, por lo tanto, el concepto de calidad. Los planes de reestructuración, propiciados por la 
PAC y las OMC del vino, han venido fomentando cierta reconversión varietal (Castelló et al, 2010). En los viñedos de la DOP Cariñena se ha apostado por la diversificación y la renovación de las variedades de uva. Las uvas tintas autóctonas, como la garnacha, ocupan actualmente menos extensión que las alóctonas, como la Tempranillo, variedad que se ha ido extendiendo continuamente desde 1993, y más recientemente otras variedades de origen francés. En las DOP de Calatayud y Campo de Borja la uva garnacha tradicional ocupa todavía la mayor extensión de su viñedo. Sin embargo, la proporción de hectáreas plantadas con variedades foráneas -un 36 por ciento en el caso del Campo de Borja y un 23 por ciento en el de Calatayud- indica que en estas DOP tampoco se excluye la elaboración de vinos a partir de estas variedades importadas de otros lugares. Del mismo modo, no puede olvidarse que en Cariñena, la uva Mazuela o Cariñena, a la que el territorio ha dado su nombre, ocupa casi el 5 por ciento del viñedo, lo cual revela la permanencia y el interés por conservar la tradición; en esta misma línea, se puede señalar la recuperación de una variedad local de uva casi olvidada, Vidadillo o Crespiello, sobre la que investigan y ensayan enólogos, viticultores y bodegas, con el apoyo del propio Consejo Regulador, habiéndose obtenido ya, con ella, algunos vinos de calidad (Loscertales, 2009 y 2011).

Figura 2

DISTRIBUCIÓN DE LAS VARIEDADES DE UVA EN LAS DOP DE LA PROVINCIA DE ZARAGOZA (2009)

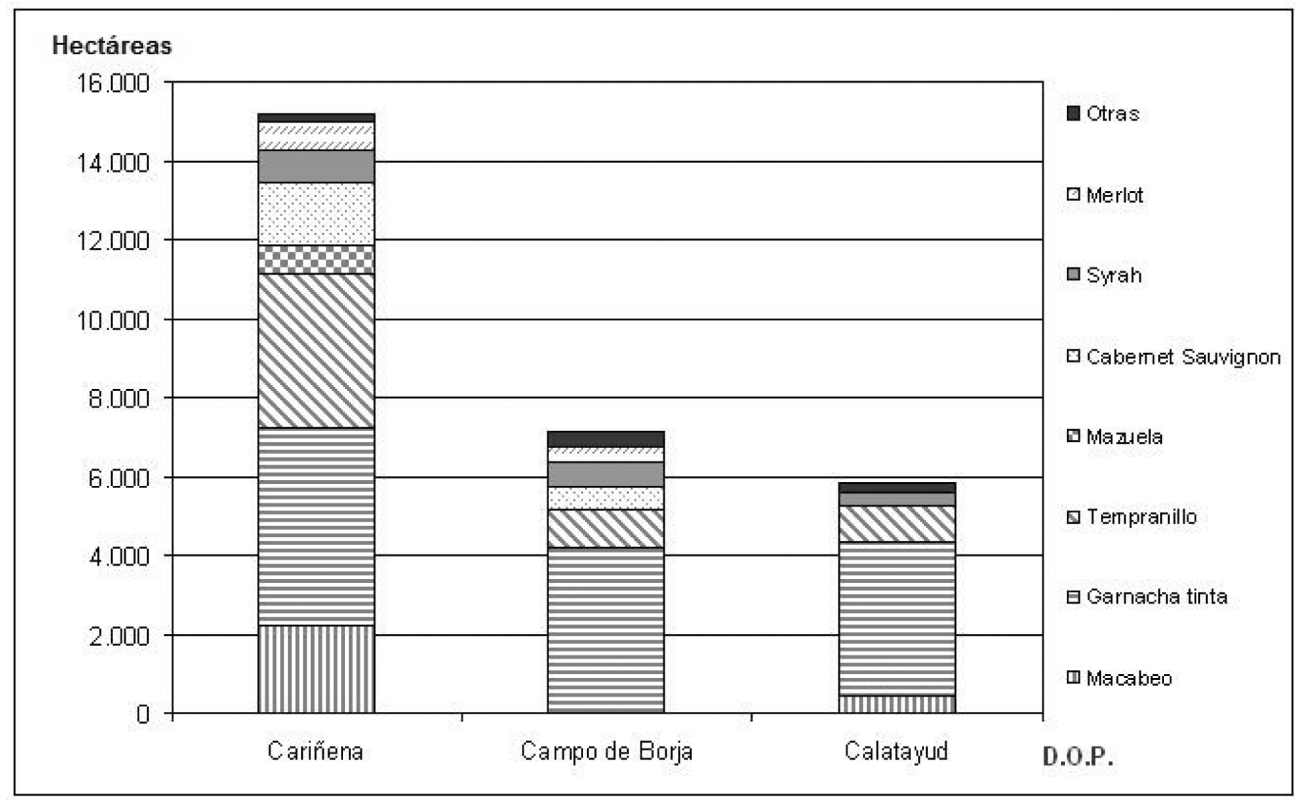

Fuente: Gobierno de Aragón.

Los vinos de las DOP Campo de Borja y Calatayud adquieren, a partir de la uva garnacha tinta, sus cualidades organolépticas, con sus aromas frutales y su paladar carnoso característicos; dichas cualidades están siendo altamente valoradas por los expertos que participan en la elaboración de las más prestigiosas guías internacionales. En Cariñena, las bodegas han 
apostado preferentemente por los coupages de distintas variedades, gracias a los cuales se obtienen vinos de aromas y sabores complejos, orientados a satisfacer a una amplia variedad de consumidores; el hecho de que actualmente esta DOP sea la sexta a nivel nacional por la cantidad de vino exportado supone un reconocimiento a dicha estrategia (Ministerio de Agricultura, Alimentación y Medio Ambiente, 2012).

La figura 3 expresa la relación entre la superficie cultivada y el empleo en el área. Las dificultades productivas recientes han ocasionado ajustes tanto en una como en otro. En la línea de lo observado en el conjunto de Aragón (Castelló et al, 2010) y de España (Ministerio de Agricultura, Alimentación y Medio Ambiente, 2012) ${ }^{3}$, se ha producido un retroceso en ambas variables, aunque se observan diferencias importantes entre las tres DOP: en Cariñena y Campo de Borja la superficie ocupada por el viñedo ha experimentado ligeras pérdidas, mientras que en Calatayud han alcanzado un $46 \%$. El número de viticultores, se ha reducido un $65 \%$ en Calatayud, un $59 \%$ en Cariñena y un $44 \%$ en Campo de Borja; en las tres gráficas se observa un punto de inflexión muy pronunciado en las campañas 2006-2007 (Campo de Borja y Cariñena) y 2008-2009 (Calatayud); a partir de entonces el descenso ha continuado, pero muy suavemente. Como el retroceso ha sido mucho mayor en el número de viticultores que en la superficie ocupada, el tamaño medio de las explotaciones se ha incrementado sensiblemente, pasando de 2,5 a 3,9 hectáreas en Calatayud, de 3,6 a 6,1 en Campo de Borja y de 4,1 a 9,5 en Cariñena.

EVOLUCIÓN DE SUPERFICIE Y VITICULTORES EN LAS DOP DE LA PROVINCIA DE ZARAGOZA

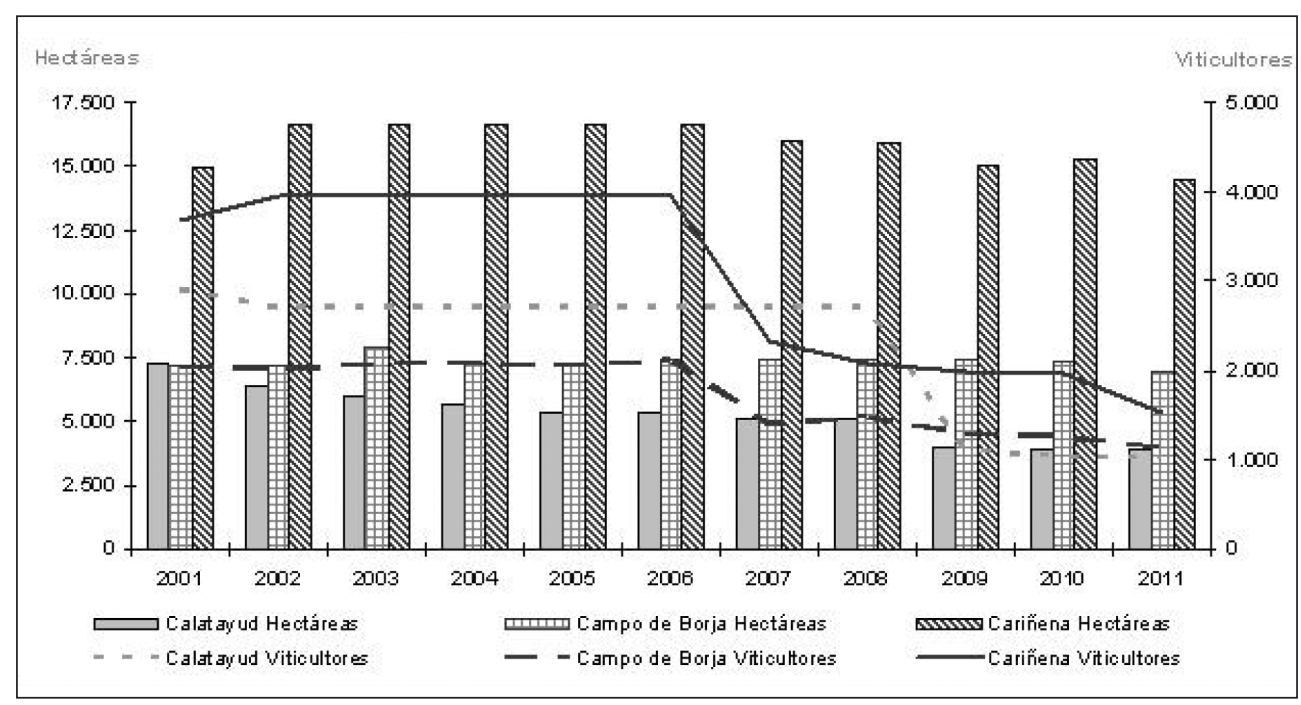

Fuente: Ministerio de Agricultura, Alimentación y Medio Ambiente, varios años.

3 Véanse los datos aportados en el primer párrafo del apartado II, subapartado 1. 


\section{LA PERCEPCIÓN DE LOS EMPRESARIOS VITIVINÍCOLAS. RESULTADOS DE LA ENCUESTA A LAS BODEGAS DE CARIÑENA, CAMPO DE BORJA Y CALATAYUD ${ }^{4}$}

La encuesta realizada a las bodegas, cuyos resultados se aportan a continuación, tenía como objeto conocer con detalle las adaptaciones productivas puestas en marcha por las empresas para mejorar su competitividad y pulsar su sentir en relación con la actual situación del sector vinícola en sus respectivos territorios. Por ello se elaboró un cuestionario cerrado estructurado en tres bloques, el primero de los cuales se centró en la caracterización de la empresa. El segundo bloque trataba de explorar la naturaleza de las estrategias empresariales y confirmar la existencia de prácticas coherentes con las expectativas suscitadas por la reestructuración vitivinícola global. Para ello se preguntó a los bodegueros por la trayectoria empresarial reciente, la organización productiva y su evolución, los canales de venta utilizados y los segmentos de calidad de los productos, entre otras. El tercer y último bloque trataba de establecer la viabilidad en las tres DOP estudiadas del nuevo paradigma rural y, en concreto, de estrategias de desarrollo basadas en la vitivinicultura. Por ello se solicitó a los empresarios que expusieran su percepción sobre el futuro de la actividad en el territorio, las estrategias que consideraban necesarias en el marco de un mercado y de una economía global, su valoración del apoyo prestado por las administraciones públicas así como sus propuestas de mejora en diversos aspectos. ${ }^{5}$

Se invitó a participar en la encuesta a todas las bodegas de las tres DOP, accediendo a hacerlo un total de 29, el 41\% del total (desglosado de la siguiente manera: el 84,6\% de Calatayud, el 62,5\% de Campo de Borja y el 16,6\% de Cariñena). Se llevó a cabo por teléfono, en marzo de 2007 (Cariñena), octubre de 2009 (Calatayud) y febrero de 2010 (Campo de Borja).

\section{Caracterización de las bodegas que forman parte de las DOP}

Las bodegas encuestadas son empresas de pequeño tamaño, como es propio de los espacios productivos tradicionales españoles y europeos (tabla 1). En la DOP Campo de Borja existe un grupo significativo de empresas de tamaño medio, pero en todo el conjunto de las tres DOP sólo un número reducido de empresas supera los 6 millones de $€$ de volumen de negocio (Loscertales, Escalona y Climent, 2011). Las formas jurídicas dominantes entre las empresas encuestadas son la cooperativa y la sociedad de capital, generalmente sociedad de responsabilidad limitada. Las cooperativas juegan un papel importante, sobre todo en la DOP Cariñena, en la que son empresas muy fuertes y controlan una parte muy significativa de la producción. En Campo de Borja y Calatayud las tres cuartas partes de las bodegas son embotelladoras, mientras que en Cariñena lo es el 56 por ciento (tabla 4).

\footnotetext{
4 Un avance de los resultados de la encuesta en la DOP Calatayud está publicado en Escalona, Loscertales y Climent (2011)

5 Los cuestionarios están publicados en Escalona et al, 2009, p. 195-198.
} 
CARACTERISTICAS DE LAS EMPRESAS ENCUESTADAS

\begin{tabular}{|l|r|r|}
\hline \multicolumn{1}{|c|}{ Aspecto } & \multicolumn{2}{c|}{ Número de empresas } \\
\cline { 2 - 3 } & Total & $\%$ \\
\hline Forma jurídica de la empresa & & \\
- Sociedad Anónima & 1 & 3,0 \\
- Sociedad de responsabilidad limitada & 16 & 55,0 \\
- Cooperativa & 8 & 27,5 \\
- Otras & 4 & 13,7 \\
\hline Año de creación & & \\
- Hasta 1959 inclusive & 6 & 20,6 \\
- Entre 1960 y 1990 & 7 & 24,1 \\
- Entre 1991 y 2000 & 8 & 27,5 \\
- Desde 2001 & 7 & 24,1 \\
- No contesta & 1 & 3,0 \\
\hline Número de trabajadores (fijos y eventuales) & & \\
- Hasta 5 & 6 & 20,6 \\
- Entre 6 y 10 & 9 & 31,0 \\
- Entre 11 y 20 & 6 & 20,6 \\
- Más de 20 & 3 & 10,3 \\
- No contesta & 5 & 17,2 \\
\hline Producción (millones de litros) & & \\
- Menos de 0,3 & 8 & 26,7 \\
- Entre 0,3 y 0,5 & 3 & 10,0 \\
- Entre 0,5 y 1 & 1 & 3,3 \\
- Más de 1 & 5 & 16,7 \\
- No contesta & & 43,3 \\
\hline
\end{tabular}

Fuente: Encuesta a los empresarios del vino.

En las empresas de la muestra tienen un peso relativo alto las familiares (12 de las 30 encuestadas), la mitad de las cuales se han mantenido durante más de una generación. Destaca igualmente el ritmo de creación empresarial, que se ha mantenido incluso en los últimos años, lo que resulta un buen síntoma en relación con el futuro de esta actividad en el territorio.

\section{La trayectoria empresarial. Principales cambios e innovaciones productivas}

La trayectoria empresarial recogida debe interpretarse en el marco de la compleja situación y expectativas de la vitivinicultura. En esta línea, el segundo bloque de la encuesta se enfoca a determinar las estrategias adoptadas tácitamente por las empresas en diferentes ámbitos para mejorar la calidad y competitividad de los productos. Las respuestas obtenidas son alentadoras porque confirman una importante actividad innovadora de las empresas, 
acorde con las prácticas contenidas en la tabla 2. De las 29 bodegas encuestadas, 20 han modificado recientemente sus estructuras productivas, lo que indica la existencia de una visión de futuro por parte de las empresas de las tres DOP. En 19 de las bodegas las modificaciones organizativas derivan de la ampliación o renovación de sus instalaciones, si bien los cambios también incorporan la introducción de otras innovaciones diversas. En esta línea, la encuesta muestra el interés de las empresas por innovar en aspectos que no son directamente de fabricación, pero que resultan esenciales para reforzar la competitividad del producto y la suya propia (figura 4).

INNOVACIONES INTRODUCIDAS POR LAS EMPRESAS

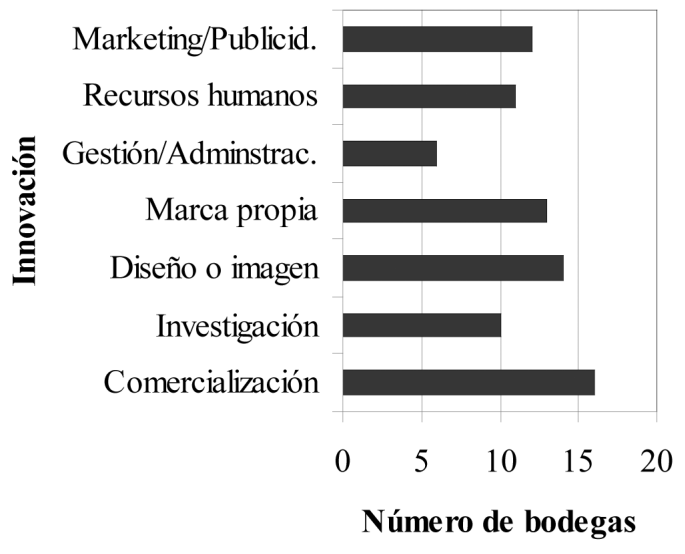

Fuente: Encuesta a los empresarios del vino (total de empresas encuestadas: 29).

Destacan las innovaciones referidas a la comercialización, relacionadas sin duda con la clara estrategia exportadora adoptada por buena parte de las bodegas para compensar el descenso del consumo y de las ventas en el mercado interno. También es clara la búsqueda de la calidad y la singularidad del producto, y para que se identifiquen estos aspectos la innovación en los ámbitos de la imagen y la marca de los productos es esencial. Son, por ello, criterios importantes para la competitividad empresarial (tabla 2). Ello también deja patente la influencia de la búsqueda de reconocimiento para la marca propia. A modo de ejemplo, podemos citar que las bodegas cuidan especialmente la presentación externa de sus vinos (tipo de botella, tapón y etiquetado, entre otros aspectos). Otras mejoras de las bodegas encuestadas reflejan la importancia de algunas prácticas enfocadas a facilitar al consumidor el seguimiento del producto desde el nacimiento de la materia prima y para darlo a conocer es frecuente encontrar en las páginas Web corporativas aplicaciones interactivas que facilitan que el consumidor conozca con detalle la trayectoria o proceso de elaboración de cualquiera de los productos de la bodega. Las bodegas se esfuerzan también por incorporar recursos humanos bien preparados en los diferentes aspectos relacionados tanto con la producción como con la gestión empresarial. 
Las innovaciones explicadas aparecen estrechamente relacionadas con la modificación de la oferta productiva, acometida por 22 de las 29 bodegas encuestadas. La elaboración de productos singulares y de calidad apreciados por los consumidores está en la base de las innovaciones introducidas en la gama habitual de vinos o en la puesta en el mercado de nuevos vinos obtenidos a partir del coupage de variedades de uva tradicionales y alóctonas (figura 5).

Figura 5

EMPRESAS SEGÚN EL TIPO DE MODIFICACIÓN EN LA OFERTA PRODUCTIVA

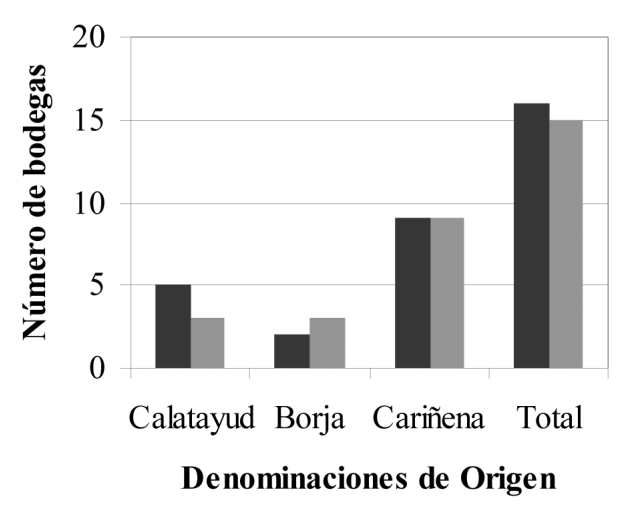

Mejora gama Nuevas variedades

Fuente: Encuesta a los empresarios del vino (total de empresas encuestadas: 29)

Cabe citar el interés que suscitan determinadas variedades o marcas de vino entre los consumidores más exigentes. Es el caso del vino de hielo, un blanco elaborado con uvas Macabeo vendimiadas en la segunda quincena de noviembre; entre sus cualidades organolépticas destaca su gran potencial aromático y un color muy intenso, siendo el primer vino de este tipo que se elabora en Aragón, de forma completamente natural. En la DOP Campo de Borja una de las principales innovaciones atañe a los vinos producidos a partir de la uva garnacha; se trata de vinos tintos monovarietales que han alcanzado un reconocido prestigio nacional e internacional.

Otro ejemplo digno de mención es el vino Pulchrum, elaborado con la uva Crespiello o Vidadillo, en la DOP Cariñena. Por último, puede citarse la campaña del Vino de las Piedras, actuación encaminada a proyectar una nueva imagen de los vinos de la DOP Cariñena: un panel de cata de expertos eligió en el presente año una selección de doce vinos exclusivos, de propiedades organolépticas bien diferenciadas, elaborados por cinco bodegas.

Generalmente, las empresas vinícolas de la muestra, sobre todo las de carácter familiar, cuentan con viñedos propios en diferentes pagos cuyas características, como ya se ha dicho, permiten la mejor adaptación a las diferentes variedades. También se dan casos en los que la explotación agraria rodea la bodega, recordando a las francesas de tipo chateau. Estas empresas orientan su estrategia a la mejora de las gamas propias, incluyendo diferentes tipos 
de vinos, entre los que destacan los elaborados a partir de variedades locales como en el caso ya citado de la garnacha, especialmente tinta. Las bodegas también innovan mediante la experimentación con otras variedades o con coupages o mezclas entre distintos vinos. Muchos de estos cambios se orientan a dar respuesta a los gustos de los consumidores sea cual sea el canal de venta utilizado (restaurantes, tiendas especializadas o grandes superficies). Otras gamas -cuya elaboración supervisan en ocasiones enólogos provenientes de los nuevos países productores- se enfocan preferentemente al mercado exportador, que como veremos más adelante, es de gran importancia para diversas empresas de las DOP estudiadas. Existen también algunas bodegas inscritas en el Comité de Agricultura Ecológica, que utilizan variedades autóctonas, destacando la garnacha (es el caso de la DOP Calatayud con un total de 44,58 has de viñedo ecológico).

La puesta en marcha de las innovaciones explicadas ha mejorado las gamas de los vinos producidos. De este modo, sólo 4 de las bodegas encuestadas afirman que elaboran vinos de gama media-baja, frente a 12 que responden que elaboran vinos de gama media y 21 de gama alta. ${ }^{6}$ Todo lo expuesto confirma el cambio de tendencia que ha tenido lugar en las bodegas de las DOP zaragozanas.

Las expectativas sobre una mejor comercialización llevan a las empresas a intentar aumentar su presencia en los mercados que consideran más atractivos. La figura 6 indica que la exportación es una vía claramente implantada entre las empresas encuestadas. No hay que olvidar que el mercado interior del vino en España atraviesa por una situación compleja debida al exceso de producción, el descenso del consumo, por la crisis y los cambios de hábitos de los consumidores, y la creciente presencia de vinos importados de otros ámbitos. Por ello la exportación en mayor o menor proporción aparece como una salida necesaria para la producción; veintidós de las veintinueve bodegas están ya presentes en los mercados internacionales. Entre 2001 y 2009 la proporción de vino exportado ha pasado del 51 al 57 por ciento del total de vino comercializado en la DOP Cariñena. También es creciente la tendencia en las DOP de Campo de Borja y Calatayud, pasando del 45 al 68 y del 29 al 48 por ciento, respectivamente. Como resultado de esta evolución, los vinos de Cariñena y Campo de Borja se venden más en el mercado internacional que en el nacional, mientras que los de Calatayud se aproximan a esa situación.

A la Unión Europea, destino habitual y todavía principal de las exportaciones, se han venido sumando más recientemente otros, especialmente los Estados Unidos, que es el país más citado por las empresas encuestadas, con once respuestas. La encuesta deja patente el esfuerzo de las empresas de las tres DOP, que han asumido plenamente el reto de la internacionalización y buscan llevar sus vinos a los nuevos consumidores, tanto si se encuentran en nuevos mercados (como hacen las empresas que mencionan su presencia en países como Finlandia, Letonia, Nueva Zelanda, Rusia, la India o México, entre otros), como si se encuentran en mercados consolidados y muy exigentes (caso de las tres empresas de la muestra que exportan a Francia).

6 Conviene valorar esta respuesta de las bodegas en el contexto general. En el caso de Cariñena (que, con ciertos matices, se puede generalizar a las otras dos DOP) las grandes cooperativas y las bodegas privadas de mayor tamaño viven fundamentalmente de la venta de vino de gama media-baja, aunque buscan obtener prestigio elaborando también vino de las gamas superiores. 
Figura 6

EMPRESAS SEGÚN EL CANAL DE VENTA, INCLUYENDO EL RECURSO A LA EXPORTACIÓN

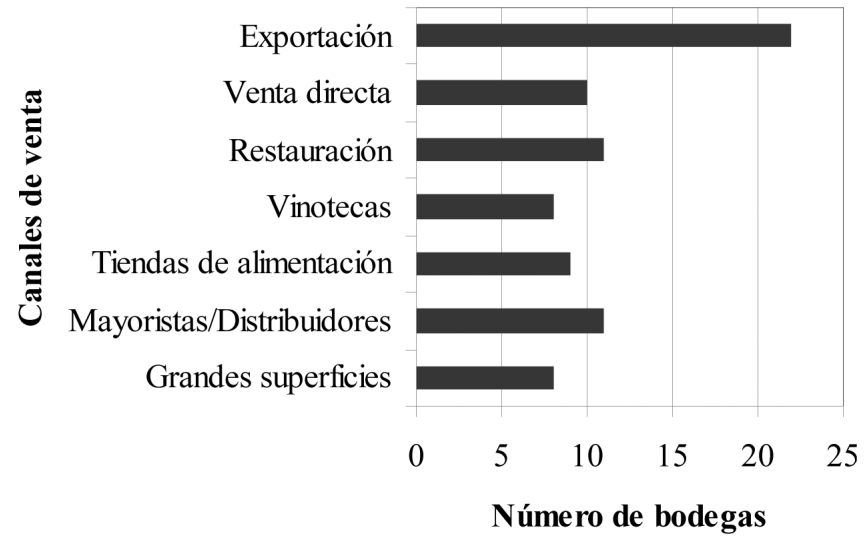

Fuente: Encuesta a los empresarios del vino (total de empresas encuestadas: 29)

La presencia en el mercado internacional de la mayor parte de las empresas no excluye que todavía en 22 de las encuestadas el principal destino de la producción sea el mercado interior. El acceso a este mercado se realiza mediante los canales de venta habituales, como expresa la figura 6. La venta a mayoristas o distribuidores y directamente en el sector de restauración o en la propia bodega ocupa un destacado lugar.

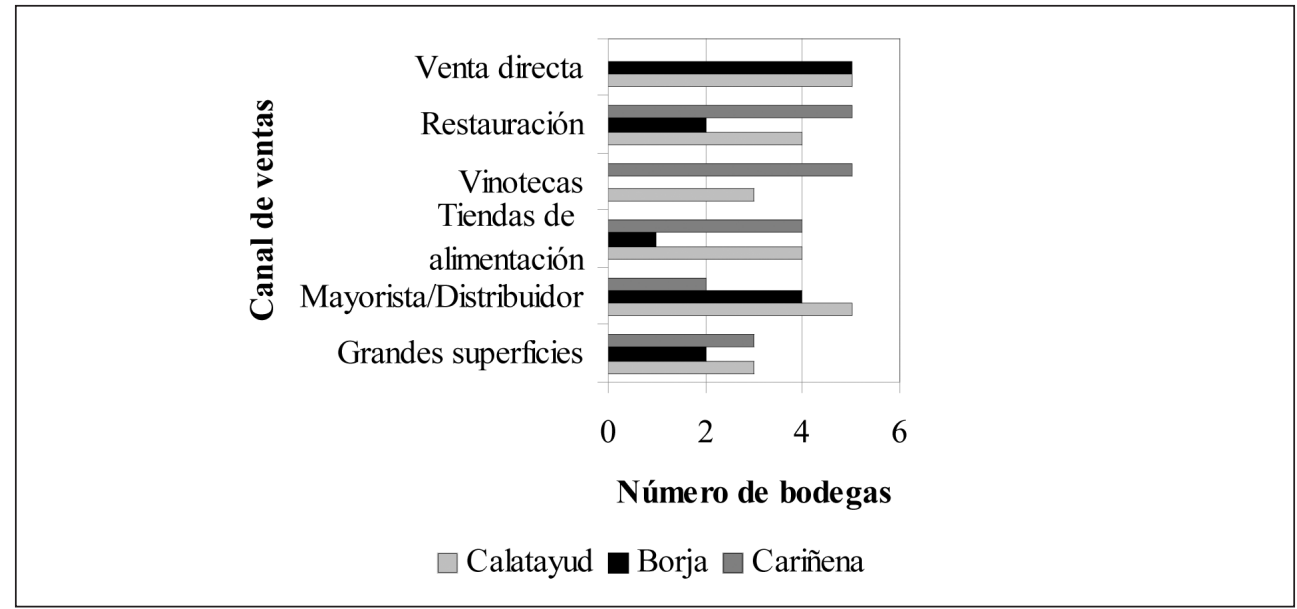

Fuente: Encuesta a los empresarios del vino (total de empresas encuestadas: 29) 
Un análisis más detallado por DOP (figura 7) muestra que en la de Calatayud se utilizan todos los canales de venta y se da también una mayor diversificación de los mismos por parte de las empresas. Tres coinciden en su preferencia por los distribuidores, a los que confían la comercialización del $100 \%$ de su producción. Una cuarta empresa, una pequeña bodega que elabora únicamente vinos de gama alta, vende el 100\% de su producción de forma directa en la propia bodega. Las demás venden a través de más de un canal, entre los que destaca la venta directa, siendo minoritaria la presencia en vinotecas y en grandes superficies. La venta directa en la bodega se practica también en la DOP Cariñena, aunque no quede recogido en la encuesta; las empresas encuestadas en la misma también utilizan ampliamente para la comercialización de sus vinos la venta directa a establecimientos de restauración y la venta en vinotecas, mientras que las empresas encuestadas pertenecientes a la DOP Campo de Borja utilizan, como segundo canal en importancia, a los mayoristas y distribuidores.

\section{Pautas para el desarrollo empresarial y territorial}

El tercer bloque de la encuesta se enfoca a verificar la hipótesis de que la vitivinicultura puede ser una herramienta para el desarrollo del espacio estudiado, según postula el nuevo paradigma rural (OCDE, 2006). En la primera pregunta del bloque, se solicita a los empresarios que manifiesten su percepción sobre la situación del sector vinícola en sus respectivas DOP. Las respuestas son diversas porque 9 de las bodegas opinan que la situación es buena; 10 responden que es preocupante y 6 que es mala. Las bodegas que dan esta última respuesta la atribuyen a los problemas generales del sector vitivinícola ya mencionados, como la alta competencia. Pero también mencionan otros aspectos de su actividad, como la falta de viticultores por el envejecimiento de la población, el arranque de viñas centenarias de calidad incentivado por las ayudas de la Unión Europea, los elevados costes, los impagos, los precios bajos a los que deben vender sus productos y, en consecuencia, la deficiente relación calidadprecio que, en su opinión, perjudica al desarrollo de la actividad. Es interesante el comentario de un empresario encuestado en la DOP Calatayud, que lamenta que sus vinos sean considerados en el mercado como «una ganga». Esta práctica de abaratar el vino es criticada en el plan estratégico para esta DOP, cuya primera recomendación es que le suban el precio automáticamente porque así el consumidor, a su vez, mejorará su percepción de la calidad del vino. La encuesta deja patente una fractura entre las cooperativas y las demás empresas, que acusan a las primeras de «deslealtad» por vender a precios bajos en un mercado ya muy saturado. También se critica a las cooperativas por pagar las uvas a bajo precio, lo que desanima a los viticultores.

Casi todas las respuestas obtenidas en la encuesta a las bodegas apuntan a que la situación del sector vitivinícola no es más compleja en sus respectivas DOP que en otras de diferentes espacios vinícolas de España. En dos respuestas se afirma que sí lo es, atribuyéndolo a que «los controles de calidad son aquí más rigurosos» y los precios más bajos. En todo caso resulta alentador que más de dos tercios de las bodegas encuestadas afirmen que la elaboración de vino puede seguir siendo sector clave para la economía y el desarrollo local. Por ello son muy interesantes las recomendaciones sobre qué estrategias empresariales de mejora deberían adoptarse en el sector. En la figura 8 se recogen las opciones propuestas en la encuesta, según la proporción de empresas que las seleccionan. 
Figura 8

ÁMBITOS PARA LA MEJORA DE LAS ESTRATEGIAS EMPRESARIALES

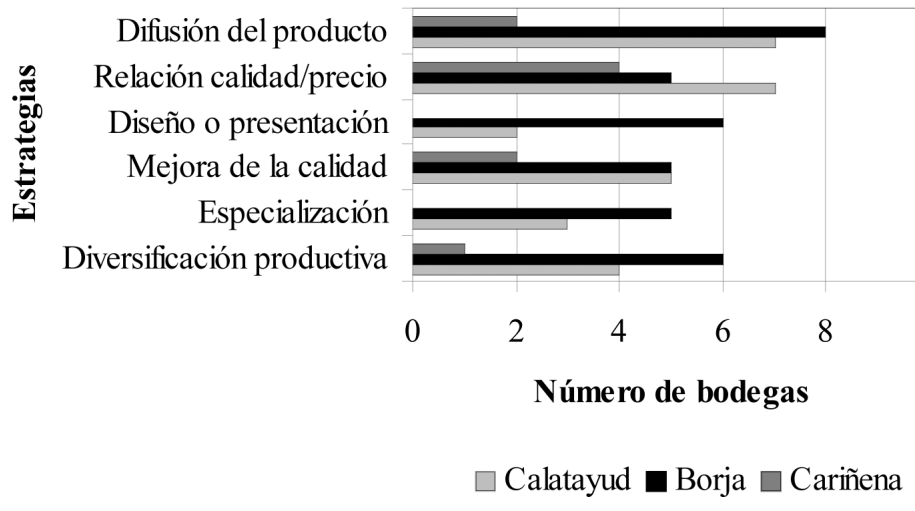

Fuente: Encuesta a los empresarios del vino (total de empresas encuestadas: 29)

La opción que suma más respuestas es la de mejorar la difusión de los productos, seguida del ajuste en la relación calidad precio, enfocado a lograr precios que remuneren más la calidad de los vinos, aspecto considerado esencial y en el que se insiste mucho. Un $40 \%$ aproximadamente de las empresas encuestadas coinciden también en recomendar mejoras en la calidad de los productos y estrategias de diversificación productiva. No se aprecian discrepancias claras entre las tres DOP. En la encuesta se solicitaba a las empresas que, además de seleccionar las estrategias propuestas, las puntuasen según su importancia. Aunque sólo seis de las encuestadas lo hicieron, nos ha parecido oportuno recoger este testimonio por su interés: consideran más prioritarias las estrategias relacionadas con el producto que con los procesos. Ello no debiera sorprender porque en el mundo del vino las innovaciones en los procesos se difunden con rapidez y es mayor el valor creado por las innovaciones centradas en los productos: las relacionadas con la difusión y mejora de la calidad, el ajuste de la relación calidad-precio y la mejora de la presentación de los vinos (botella y etiquetado).

Si se desagregan los resultados por bodega, llama la atención el escaso nivel de coincidencia entre unas y otras al priorizar sus estrategias. Ni siquiera las cooperativas coinciden en su recomendación (tabla 5). Los datos manejados no permiten inferir los motivos por los cuales hay discrepancia, aunque quizás puede ser consecuencia de la heterogeneidad de situaciones empresariales y, por tanto, de la diversidad de puntos de vista sobre qué estrategias productivas son más adecuadas en los tiempos actuales. Refleja también la necesidad de que los gestores económicos y territoriales definan líneas precisas de actuación y asuman un necesario liderazgo.

En esta línea, la encuesta deja patente que las Administraciones Públicas deben mejorar la función que vienen desempeñando. Es lo que opinan dieciocho de las veintinueve bodegas encuestadas, cuyas propuestas para una mejor gestión pública se consignan en la tabla 6 . Cuatro bodegas reclaman ayudas específicas en el ámbito de la promoción y búsqueda de 
Tabla 5

VALORACIÓN DE LAS ESTRATEGIAS DE MEJORA Y CARACTERISTICAS DE LAS EMPRESAS QUE LA REALIZAN

\begin{tabular}{|c|c|c|c|c|c|c|c|c|c|}
\hline \multirow[b]{2}{*}{ 鹃 } & \multicolumn{3}{|c|}{ Datos Básicos } & \multicolumn{6}{|c|}{$\begin{array}{l}\text { Ámbitos de mejora recomendados } \\
\text { (de 1, el que más, a 6, el que menos) }\end{array}$} \\
\hline & 苞 & 离 & 包 & $\begin{array}{l}\text { Diversifi- } \\
\text { cación de } \\
\text { producto }\end{array}$ & Calidad & $\begin{array}{c}\text { Botella y } \\
\text { etiquetado }\end{array}$ & $\begin{array}{l}\text { Especia- } \\
\text { lización }\end{array}$ & $\begin{array}{c}\text { Ajuste } \\
\text { relación } \\
\text { calidad- } \\
\text { precio }\end{array}$ & $\begin{array}{c}\text { Difusión } \\
\text { del } \\
\text { producto }\end{array}$ \\
\hline 1 & Cooper & 0 & 0 & 5 & 1 & 6 & 4 & 3 & 2 \\
\hline 2 & Cooper & 8 & 60 & 5 & 3 & 2 & 6 & 4 & 1 \\
\hline 3 & Comand & 10 & 50 & 1 & 6 & 3 & 2 & 4 & 5 \\
\hline 4 & Cooper & 2 & 0 & 1 & 6 & 3 & 2 & 5 & 4 \\
\hline 5 & Cooper & 5 & 0 & 6 & 2 & 5 & 1 & 3 & 4 \\
\hline 6 & SRL & 7 & 5 & 5 & 1 & 6 & 2 & 4 & 3 \\
\hline
\end{tabular}

* «Cooper»: Cooperativa. «Comand»: Sociedad comanditaria. «SRL»: Sociedad de Responsabilidad Limitada. Fuente: Encuesta a los empresarios del vino.

nuevos mercados y una las cree necesarias debido a la crisis que afecta al sector. Es muy interesante la propuesta de otra bodega que demanda recursos para realizar acciones de promoción pequeñas y con gran impacto, porque percibe que las grandes acciones institucionales no llegan al cliente final.

Tabla 6

PROPUESTAS DE LAS BODEGAS PARA MEJORAR EL APOYO DE LAS ADMINISTRACIONES PÚBLICAS

\begin{tabular}{|l|l|}
\hline \multicolumn{1}{|c|}{ Ámbito de aplicación } & \multicolumn{1}{c|}{ Propuesta de las bodegas en sus respuestas } \\
\hline Subvención & $\begin{array}{l}\text { Conceder ayudas para hacer frente a la crisis. } \\
\text { Subvencionar a las pequeñas empresas }\end{array}$ \\
\hline Normativa & $\begin{array}{l}\text { Facilitar la aplicación por las empresas, relajando los controles de } \\
\text { seguridad percibidos como excesivos y, en general, simplificando } \\
\text { las diferentes tramitaciones }\end{array}$ \\
\hline $\begin{array}{l}\text { Dinamización } \\
\text { empresarial }\end{array}$ & $\begin{array}{l}\text { Dispensar a todas las empresas el mismo trato para evitar situacio- } \\
\text { nes de competencia desleal. } \\
\text { Apoyar las buenas prácticas y penalizar la mala gestión }\end{array}$ \\
\hline Desarrollo rural & Aplicar la normativa vigente \\
\hline Promoción & $\begin{array}{l}\text { Realizar acciones conjuntas de promoción en mercados exteriores } \\
\text { Proporcionar recursos para la realización de acciones de promo- } \\
\text { ción pequeñas y con gran impacto, que lleguen al cliente final }\end{array}$ \\
\hline
\end{tabular}

Fuente: Encuesta a los empresarios del vino. 
La última parte de la encuesta se refiere a las relaciones entre la bodega y su territorio. Se buscaba confirmar la interdependencia positiva entre el territorio y las producciones locales, aspecto que constituye uno de los supuestos del nuevo paradigma rural. En opinión de Maby (2000), dicha interdependencia haría del territorio un elemento activo para el desarrollo de los productos y éstos, por su parte, se convertirían en embajadores del territorio. La Denominación de Origen Protegida es un marco que facilita la asociación explícita del producto, sus características y calidad con el territorio en el que se obtiene y con las prácticas culturales que le son propias. Por ello, una de las preguntas formuladas a las bodegas se orientó sobre las ventajas que proporciona la pertenencia a una denominación de origen protegida. Las respuestas muestran un contraste de pareceres: para 19 bodegas formar parte de una DOP es un factor positivo, pero las 10 restantes no le ven ventajas. Entre las razones que éstas aducen para justificar su afirmación, está la percepción de una desigualdad de trato a las bodegas o la apreciación de que en los momentos actuales la pertenencia a una DOP supone una limitación del potencial productivo de la empresa. Otra bodega critica que el «paraguas» de la DOP impide que el cliente llegue a conocer realmente las características específicas del terrazgo en el que se obtiene el vino.

Estos resultados son interesantes porque recogen el debate actual sobre la figura jurídica de la Denominación de Origen Protegida. Sin embargo, la mayoría de las bodegas sí apoya que la imagen de los vinos se promocione asociada al territorio. Algunas de las 17 bodegas que manifiestan esa opinión la justifican porque los vinos contribuyen a la promoción y al desarrollo endógeno de sus territorios. Ello confirma que los empresarios del sector son conscientes de que su actividad genera en el territorio alguno de los beneficios a las que nos referíamos en el apartado tercero. De otras respuestas se deduce el aprecio de los diferentes actores por los valores territoriales propios, al conocer que los caracteres singulares que aportan a los vinos son altamente valorados por determinados segmentos de consumidores. Los actores perciben que el territorio y su historia influyen positivamente en la promoción de los vinos, porque les confieren señas de identidad, un carácter «exclusivo» y un valor emocional que «ayuda a fidelizar clientes».

\section{CONCLUSIÓN}

La mundialización productiva, fenómeno característico del cambio de siglo, viene afectando a las áreas rurales especializadas en productos cuyo mercado se ha ampliado y complicado, en los aspectos relacionados tanto con la oferta como con la demanda. Las áreas vitivinícolas españolas, como las aragonesas estudiadas en el artículo, deben operar en un mercado con más y mejores competidores y con exceso de oferta en algunos segmentos de demanda, a lo que sólo puede hacerse frente llegando a nuevos consumidores y a los nuevos mercados emergentes. Los procesos citados plantean nuevos retos a las empresas y tienen un amplio impacto en los territorios, debido a la estrecha y antigua relación entre la actividad vitivinícola y la trayectoria territorial. En las tres DOP de la provincia de Zaragoza estudiadas, las diversas características del territorio y la tradición preindustrial están en el origen de los vinos, que deben también su singularidad a otros factores como el clima, el tipo de uva autóctona dominante (la garnacha tinta) o el «saber hacer», fruto de su propia historia económica. 
Hemos sintetizado los enfoques y estrategias que postulan teorías reconocidas, como la de las convenciones y la del nuevo paradigma rural y hemos presentado la experiencia de una muestra de bodegas de las tres DOP zaragozanas a partir de los resultados de una encuesta sobre la adopción de dichas estrategias empresariales y territoriales. Creemos haber demostrado el interés y el esfuerzo que realizan en las bodegas, pequeñas en su inmensa mayoría, por adecuar sus procesos y, sobre todo, sus productos, para facilitar que los vinos consoliden sus mercados o entren en otros nuevos. La encuesta ha dejado también patente una inquietante fractura entre bodegas cuya titularidad corresponda a sociedades de capital y las sociedades cooperativas y una notable dispersión en las trayectorias empresariales, lo que pudiera ser sintomático de una falta de liderazgo en el seno del sector.

La anterior apreciación nos ha llevado a plantear la necesidad de un mejor apoyo de las administraciones públicas a estas actividades. Ello es coherente con los nuevos modelos para el desarrollo rural, enfocados a que las áreas afectadas por procesos de mundialización en sectores básicos de sus economías superen con éxito los actuales retos. Entre dichos modelos, hemos destacado el nuevo paradigma rural, que propugna el apoyo a las especificidades productivas del territorio como herramienta adecuada para estimular el desarrollo rural en el marco de la mundialización. En esta línea, el artículo ha ofrecido evidencias suficientes para afirmar que la producción de vino, que singulariza a las áreas estudiadas, puede cumplir plenamente el papel que el modelo citado asigna a las especificidades territoriales. Por una parte, hemos explicado alguno de los beneficios intrínsecos que, a modo de externalidades positivas, aporta al territorio. Por otra, hemos mostrado el aprecio de los empresarios por el territorio en el que se ubican y su conocimiento de los que éste aporta al carácter y singularidad de sus vinos. Las propuestas realizadas desde las diferentes bodegas tienen un gran interés para que las administraciones públicas mejoren el apoyo que vienen brindando a esta actividad.

Todo lo expuesto viene a confirmar, para las tres DOP estudiadas, la existencia de una interdependencia positiva entre el territorio y las producciones locales y que éstas pueden seguir siendo herramientas para mejorar la competitividad de aquél.

\section{BIBLIOGRAFÍA}

AMILIEN, V., FORT, F., FERRAS, N. (2007): «Hyper-real territories and urban markets: changing conventions for local food. Case studies from France and Norway». Anthropology of Food, Special Issue, $\mathrm{n}^{\circ}$ 2. Disponible en http://aof.revues.org/document446.html

ALBISU AGUADO, L.M. (2004): «Estrategias empresariales y mercado internacional del vino». Quaderns Agroambientals, nº 5, 9-22.

APARICIO, J., SÁNCHEZ, J.L., ALONSO, J.L y RODERO, V. (2008): «La Ribera del Duero, geografía de un medio innovador en torno a la vitivinicultura». Scripta Nova. Revista Electrónica de Geografía y Ciencias sociales $\mathrm{n}^{\circ} 277$. Disponible en http://www.ub.es/geocrit/sn/sn-277.htm.

BARCO ROYO, E. (2007): «Denominaciones de origen». Distribución y consumo, $\mathrm{n}^{\circ}$ 96, $27-41$

BARCO ROYO, E., LANGREO NAVARRO, A. y NAVARRO PÉREZ, M.C (2005): «Cambios en el mercado internacional del vino». Distribución y consumo, no 80, 53-64. 
BARCO ROYO, E., PINILlOS GARCÍA, M.O. y NAVARRO PÉREZ, M.C. (2006): «Estrategias de diversificación versus estrategias de tamaño». Cuaderno de Campo, ${ }^{\circ}$ 34, 12-16.

CASTELLÓ PUIG, A., FRUTOS MEJÍAS, L.M., HERNÁNDEZ NAVARRO, M.L., LOSCERTALES PALOMAR, B. y RUIZ BUDRÍA, E. (2010): «Los paisajes vitivinícolas en la economía rural aragonesa» en Territorio, paisaje y patrimonio rural. XV Coloquio de Geografía Rural. Cáceres, Universidad de Extremadura, 49-61.

CLIMENT LÓPEZ, E., ESCALONA ORCAO, A.I. y LOSCERTALES PALOMAR, B. (2011). «Reestructuración productiva en los distritos industriales españoles del calzado: el caso de Illueca-Brea de Aragón» en Scripta Nova. Revista Electrónica de Geografía y Ciencias Sociales, vol. XV, $\mathrm{n}^{\circ}$ 375, 20 de septiembre de 2011. Universidad de Barcelona. Disponible en http://www.ub.es/geocrit/sn/sn-375.htm

ESCALONA ORCAO, A.I., LOSCERTALES PALOMAR, B. y CLIMENT LÓPEZ, E. (2009): Nuevos retos para el desarrollo territorial: los espacios del vino y del calzado en la provincia de Zaragoza. Zaragoza. Diputación Provincial de Zaragoza. Disponible en http://www.dpz.es/diputacion/areas/presidencia/4espacio/documentos/premios/nuevos_retos_territorial09.pdf

ESCALONA ORCAO, A.I., LOSCERTALES PALOMAR, B. y CLIMENT LÓPEZ, E. (2010): «Nuevos retos empresariales en las áreas rurales. Convenciones y estrategias de las industrias del vino y del calzado en la provincia de Zaragoza» en Actas del XII Congreso Ibérico de Geografía (en prensa).

ESCALONA ORCAO, A.I., LOSCERTALES PALOMAR, B. y CLIMENT LÓPEZ, E. (2011): «Convenciones, prácticas empresariales y pautas para el desarrollo económico y territorial. Las industrias del vino y del calzado en la provincia de Zaragoza». Anales de Geografía de la Universidad Complutense, $\mathrm{n}^{\circ}$ 2, 153-178.

FRUTOS, L.M.; CASTELLÓ, A.; CLIMENT, E.; ESCALONA, A.; HERNÁNDEZ, M.; LOSCERTALES, B y RUIZ-BUDRÍA, E. (2011): «Conventions theory and quality strategies in the international wine market». Wine in the World: Markets and Globalisation. Fourth International Conference on Economics, Management Sciences and History of Wine. Zaragoza June $29^{\text {th }}$-July $1^{\text {st }}, 2011$. Disponible en http://estructuraehistoria.unizar. es/gihea/documents/Frutosetalii_comunicacion.pdf

LINDKVIST, K.B. y SÁNCHEZ, J.L. (2008): «Conventions and innovation: a comparison of two localised natural resource-based industries». Regional Studies, n 42, 343-354.

LOSCERTALES PALOMAR, B. (2009): La denominación de Origen Cariñena: una apuesta por la singularidad y la calidad en un mundo globalizado. Zaragoza. Diputación Provincial de Zaragoza, Institución Fernando el Católico.

LOSCERTALES PALOMAR, B. (2011) «La denominación de origen vitivinícola de Cariñena» en Nuevos espacios productivos en Aragón: innovación y tradición. IV Jornadas de Campo de Geografía Económica. Zaragoza, Universidad de Zaragoza, 15-40

LOSCERTALES PALOMAR, B., ESCALONA ORCAO, A.I. y CLIMENT LÓPEZ, E. (2011): «Cambios recientes en el sector vitivinícola: el caso de las denominaciones de origen zaragozanas». Geographicalia, n 59-60, 227-240.

MABY, J (2000): «Le vin, argument identitaire du territoire». Roma, Comunicación presentada al Congreso sobre Una nueva Geografía del vino. 
MINISTERIO DE AGRICULTURA, PESCA Y ALIMENTACIÓN (2006): Estrategia para el vino en España 2007-2010. Madrid, Ministerio de Agricultura, Pesca y Alimentación.

MINISTERIO DE AGRICULTURA, ALIMENTACIÓN Y MEDIO AMBIENTE (varios años): Datos de las Denominaciones de Origen Protegidas de vinos. Disponible en http://www.magrama.gob.es/es/alimentacion/temas/calidad-agroalimentaria/calidad-diferenciada/dop/htm/cifrasydatos.aspx

MURDOCH, J., MIELE, M. (1999): «Back to Nature: changing 'worlds of production' in the food sector». Sociologia Ruralis, $\mathrm{n}^{\circ} 39,465-483$.

OBSERVATORIO ESPAÑOL DEL MERCADO DEL VINO (2010): «2009, un año difícil para las exportaciones de vino». Disponible en http://www.oemv.es/noticia_amp. php?id=00000017012

OCDE (2006): The New Rural Paradigm: Policies and Governance. Paris

PONTE, S. (2009): «Governing through quality: conventions and supply relations in the value chain for South African wine». Sociologia Ruralis, n 49, 236-257.

SALAIS, R., STORPER, M. (1992): «The four 'worlds' of contemporary industry». Cambridge Journal of Economics, $\mathrm{n}^{\circ}$ 16, 169-193.

SÁNCHEZ, S. y ARÉVALO, P. (2007): «Globalización, industria tradicional y territorio en Castilla-La Mancha». Anales de Geografía, n 27, 103-124.

SÁNCHEZ-HERNÁNDEZ, J.L., APARICIO-AMADOR, J., ALONSO-SANTOS, J.L. (2010): «The shift between worlds of production as an innovative process in the wine industry in Castile and Leon (Spain)». Geoforum, n 41, 469-478.

SCHAMP, E. (2005): «Decline of the district, renewal of firms: an evolutionary approach to footwear production in the Pirmasens area, Germany». Environment and Planning, ${ }^{\circ} 37$, 617-634.

SCOTT, A. (2006): «The changing global geography of low-technology, labour-intensive industry: clothing, footwear and furniture». World Development, $\mathrm{n}^{\circ} 34,1517-1536$.

SOMMERS, B.J. (2008): The Geography of Wine: How Landscapes, Cultures, Terroir, and the Weather Make a Good Drop. Londres. Penguin.

STORPER, M. (1997): The Regional World. Territorial Development in a Global Economy. Nueva York. Guilford Press. 
